\title{
Improvement of Health Education: The Opportunities of Technology and Digital Learning Tools
}

\section{Brynjar Foss* and Cecilie Haraldseid}

Department of Health Studies, University of Stavanger, Norway

Technology is an important aspect of health, it is found in e.g. hightech apparatus in surgery rooms and as hospital laboratory equipment. In addition technology is now rapidly entering education as well. Games, podcasts, e-compendiums, Massive Open Online Course (MOOC) and simulation tools are all technological based learning tools increasingly used in higher education.

One of the goals of introducing digital learning tools is obviously to achieve better skilled students so that they ultimately will become better health workers. The aims of digital learning tools are multifaceted, serve different purposes and give a number of opportunities. Some tools simply make distance education possible and flexible $[1,2]$ and thereby facilitates the needs of a larger student mass to fill the gap of health workers in lac. Other digital learning tools add enjoyment and/or build confidence in learning $[3,4]$ aiming to help the struggling students to complete their education. While yet others improve learning $[2,4-$ 6]. Another aspect not to underestimate is that students today are exposed to a media rich environment that has made them experts in technological multitasking, causing them to expect and demand innovative technological tools to be integrated in their educational programs in order to echo their technological skills [7-10]. It is therefore a goal to combine the newest within technology with learner-active, student centered, pedagogical methods.

\section{Digital Learning Tools for Theoretical Skills}

In 2009 the current form of distance nursing education was introduced at the University of Stavanger (UiS), Norway. To meet these students' needs, different digital learning tools were developed. This includes e-compendiums, i.e. electronic rich media PDF files containing audio files, figures, photos, animations, interactions and a short multiple-choice test, podcasts and two games [11]. What is interesting is that, compared to lectures, text books, podcasts, digital multiple choice questionnaires and task solving, the e-compendiums was regarded as the best learning tool among our students [11]. The e-compendiums offer flexibility by giving students the opportunities to alternate between reading, listening and writing and to use the tool on their laptops. And it is reason to believe that the digital format was the explanation for the good score of these e-compendiums.

Another tool developed at UiS is the medication game - Pill Play - which purpose is to drill the student nurses on mathematical skills relevant for medication calculation [12]. Our randomized controlled trial showed that the exam failure rate was lower among the gamers compared to controls, however not significantly. Yet, the gamers who passed the exam had better high score compared to gamers who failed the exam [13], suggesting that the game might be just as useful learning tool to improve learning as other more traditional learning methods. As previously described [3] games constitute a learning tool that can improve learning outcomes, and thus, clearly open new opportunities in higher education. In fact, dueto our results the Pill Play is now embedded in our new medication calculation MOOC. By designing MOOCs likes this, health education becomes even more flexible and student centered.

\section{Digital Learning Tools for Practical Skills}

Simulation has increasingly developed to become a highly advanced technology based learning tool [14] that is clearly one answer to how we can drill students on practical skills. Teaching and learning clinical skills is a complex process that requires different educational approaches and multiple repetitions for the student to learn. While face-to face learning is important, the students also need the chance to rehearse repeatedly and receive feedback when they are on their own. Laerdal Medical's new simulation tool SimPad ${ }^{\circledR}$, has given us the opportunity to preprogram various scenarios that students can run and operate on their own. The scenarios challenge the students to critical thinking, decision making, and integration of all the different aspects of nursing care at the same time. SimPad ${ }^{\circledR}$ is a wireless, portable tool with a touchscreen interface that gives both experienced and inexperienced instructors the opportunity to operate and run scenarios. The integration of this new technology with the complexity of learning clinical skills and how this influence the students learning process is therefore now an ongoing research project at the UiS.

\section{Improving Health Education?}

Technical solutions and digital learning tools offer various opportunities in health education. Reading text with interactions (e-compendiums), listen on the go (podcast), drilling skills by playing (games) and practical training (simulation) - these are all tools that meet the demands of the new generation. It gives them the opportunity to select among different learning tools, learn at new places, with new methods and thereby help the students to memorize, drill, reflect and apply their knowledge on their own terms. We believe that using the potential of digital learning tools and methods as supplement to other more traditional learning will improve health education in the long run. This is because these tools create variation, immediate feedback, enthusiasm can easily be used to drill specific topics or procedures and they may even be fun.

\section{References}

1. Burgess $L$ (2003) WebCT as an E-learning tool: Study of technology students preceptions. Journal of Technology Education 15: 6-14.

2. Singh M (2010) M -learning: A new approach to learn better. International Journal of Education and Allied Sciences 2: 65-72.

3. Blakely G, Skirton H, Cooper S, Allum P, Nelmes P (2009) Educational gaming in the health sciences: Systematic review. Journal of Advanced Nursing 65: 259-269.

*Corresponding author: Brynjar Foss, Department of Health Studies, University of Stavanger, 4036 Stavanger, Norway, Tel: +47 992507 87; E-mail: brynjar.foss@uis.no

Received January 29, 2014; Accepted January 31, 2014; Published February 02, 2014

Citation: Foss B, Haraldseid C (2014) Improvement of Health Education: The Opportunities of Technology and Digital Learning Tools. J Biosafety Health Educ 2: e114. doi:10.4172/2332-0893.1000e114

Copyright: (c) 2014 Foss B, et al. This is an open-access article distributed under the terms of the Creative Commons Attribution License, which permits unrestricted use, distribution, and reproduction in any medium, provided the original author and source are credited. 
Citation: Foss B, Haraldseid C (2014) Improvement of Health Education: The Opportunities of Technology and Digital Learning Tools. J Biosafety Health Educ 2: e114. doi:10.4172/2332-0893.1000e114

4. Douglas M, Wilson J, Ennis S (2012) Multiple-choice question tests: a convenient, flexible and effective learning tool? A case study. Innovations in Education and Teaching International 49: 111-121.

5. Hassanien A (2006) An evaluation of the webquest as a computer-based learning tool. Research in Post-Compulsory Education 11: 235-250.

6. Laru J, Näykki P, Järvelä S(2012) Supporting small-group learning using multiple Web 2.0 tools: A case study in the higher education context. The Internet and Higher Education 15: 29-38.

7. Lin ZC (2013) Comparison of technology-based cooperative learning with technology-based individual learning in enhancing fundamental nursing proficiency. Nurse Education Today 33: 546-551.

8. Gabriel M, Campbell B, Wiebe S, MacDonald RJ, McAuley A (2012) The role of digital technologies in learning: Expectations of first year university students Canadian Journal of Learning and Technology 38.

9. Owens JD, Floyd D (2007) E-learning as a Tool for Knowledge Transfer through Traditional and Independent Study at Two United Kingdom Higher Educational Institutions: a case study. E-Learning and Digital Media 4: 172-180.
10. Percival JC, Muirhead B (2009) Prioritizing the implementation of e-learning tools to enhance the learning environment. Journal of Distance Education 23 89-106.

11. Foss B, Oftedal BF, Løkken A (2013) Rich media e-compendiums: A new tool for enhanced learning in higher education. European Journal of Open, Distance and E-Learning 16: 102-114.

12. Foss B, Mordt P, Oftedal B, Løkken A (2013) Medication calculation: The potential role of digital game-based learning in nurse education. CIN: Computers, Informatics, Nursing 31: 589-593.

13. Foss B, Løkken A, Leland A, Stordalen J, Mordt P, et al. (2014) Digita game-based learning: a supplement for medication calculation drills in nurse education. E-learning and Digital Media 11.

14. Bailey C, Johnson-Russell J, Lupien A (2011) High-fidelity patient simulation. In: J. BM, A. HJ, editors. Innovative teaching strategies in nursing and related health professions 5. Sudbury, MA: Jones \& Bartlett 207-226. 